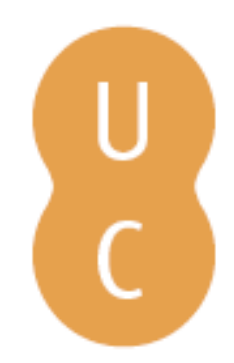

\title{
pommalina
}

\section{O sistema alimentar da cidade do Rio de Janeiro na primeira metade do século XIX: entre a conservação e a transformação}

\author{
Autor(es): $\quad$ Sene, Gláucia Malerba; Morgado, Andrea Jundi; Locks, Martha \\ Publicado por: Imprensa da Universidade de Coimbra \\ URL \\ persistente: URI:http://hdl.handle.net/10316.2/45258 \\ DOI: $\quad$ DOI:https://doi.org/10.14195/978-989-26-1720-6_18 \\ Accessed : $\quad$ 26-Apr-2023 03:16:26
}

A navegação consulta e descarregamento dos títulos inseridos nas Bibliotecas Digitais UC Digitalis, UC Pombalina e UC Impactum, pressupõem a aceitação plena e sem reservas dos Termos e Condições de Uso destas Bibliotecas Digitais, disponíveis em https://digitalis.uc.pt/pt-pt/termos.

Conforme exposto nos referidos Termos e Condições de Uso, o descarregamento de títulos de acesso restrito requer uma licença válida de autorização devendo o utilizador aceder ao(s) documento(s) a partir de um endereço de IP da instituição detentora da supramencionada licença.

Ao utilizador é apenas permitido o descarregamento para uso pessoal, pelo que o emprego do(s) título(s) descarregado(s) para outro fim, designadamente comercial, carece de autorização do respetivo autor ou editor da obra.

Na medida em que todas as obras da UC Digitalis se encontram protegidas pelo Código do Direito de Autor e Direitos Conexos e demais legislação aplicável, toda a cópia, parcial ou total, deste documento, nos casos em que é legalmente admitida, deverá conter ou fazer-se acompanhar por este aviso.

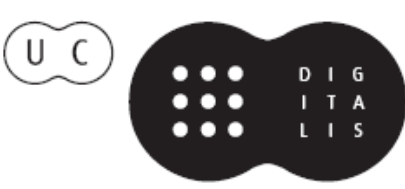


Carmen Soares

\section{Cilene da Silva Gomes Ribeiro}

\section{(coords.)}

MESAS

\section{ALIMENTAÇÃ O, SAÚDE \& CULTURA}

\section{IU LUO-BRASILEIRAS}

\section{VOLUME II}

IMPRENSA DA UNIVERSIDADE DE COIMBRA

COIMBRA UNIVERSITY PRESS

PUCPRESS 


\title{
O sistema Alimentar da Cidade do Rio de JANEIRO NA PRIMEIRA METAdE do SÉculo XIX
}

(The food system in the first half of $19^{\text {th }}$ century Rio de Janeiro)

\author{
Entre a CONSERVAÇÃo E A TransformaÇão
}

(Between conservation and shifting)

\author{
Gláucia Malerba Sene \\ Universidade do Estado do Rio de Janeiro, \\ Departamento de Arqueologia \\ GMALERBA@HOTMAIL.COM \\ Andrea Jundi Morgado \\ Contexto ARQueologia \\ ANDREA.JUNDI6@GMAIL.coM \\ Martha Locks \\ Museu Nacional / Universidade Federal do Rio \\ de Janeiro, Departamento de Antropologia \\ MLOCKS $@_{\text {MN.UFRJ.BR }}$ \\ Tania Andrade Lima \\ Museu Nacional / Universidade Federal do Rio de Janeiro \\ TALIMA8@GMAIL.COM
}

Resumo: Este artigo apresenta uma síntese da cultura material relacionada ao sistema alimentar de unidades residenciais do século XIX, localizadas à rua Riachuelo, centro do Rio de Janeiro, aí compreendidos restos faunísticos, recipientes cerâmicos e louças utilizadas no serviço e consumo dos alimentos. A análise desses componentes revelou algumas contradições do sistema sociocultural da primeira metade desse século no Rio de Janeiro. Embora passando por grandes transformações em vários níveis e já se deixando permear pelos valores franco-ingleses em ascensão, no nível das práticas alimentares cotidianas, essa ambivalente sociedade em transição parece ter conservado predominantemente as tradições culinárias dos colonizadores, das quais só viria a se libertar de meados do século em diante.

Palavras-chave: arqueologia urbana, Rio de Janeiro oitocentista, faiança fina inglesa, ossos animais, multiculturalismo. 


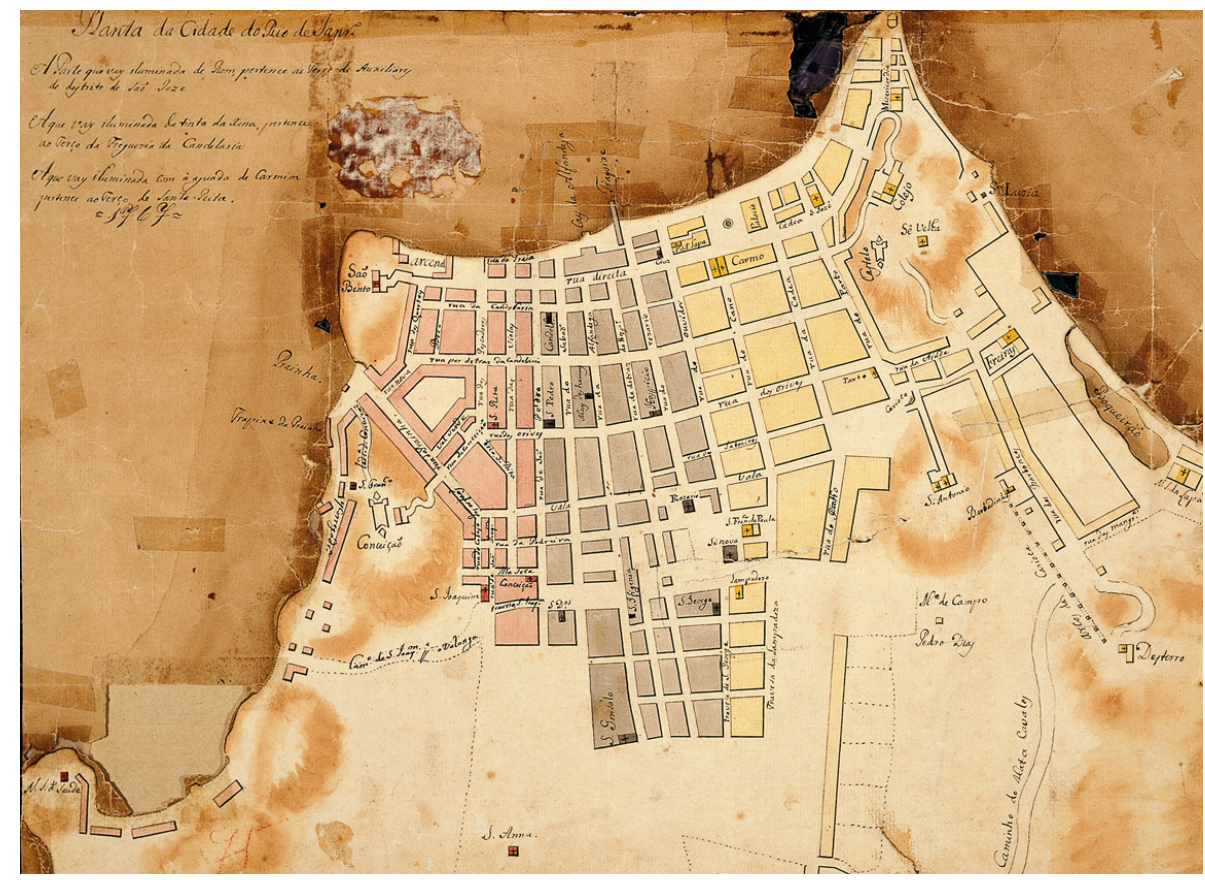

Figura 1: Planta da Cidade do Rio de Janeiro, de 1767

Nota: Vê-se, à direita, o Caminho de Mata Cavalos serpenteando junto às faldas do Morro do Desterro. A seta no trecho inferior aponta a localização aproximada, à época, da área pesquisada.

Fonte: http://www.sudoestesp.com.br/file/colecao-imagens-periodo-colonial-rio-janeiro

Em função dessa trajetória, era esperado que fossem encontrados no terreno do empreendimento testemunhos das ocupações iniciais à margem do velho caminho, ou ao menos remanescentes de edificações do século XVIII. Surpreendentemente, no entanto, as escavações expuseram os alicerces em alvenaria de pedra de seis unidades habitacionais do século XIX, associados a uma abundante cultura material também do mesmo período, relacionada à vida cotidiana das famílias que ali viveram (Figura 2). 


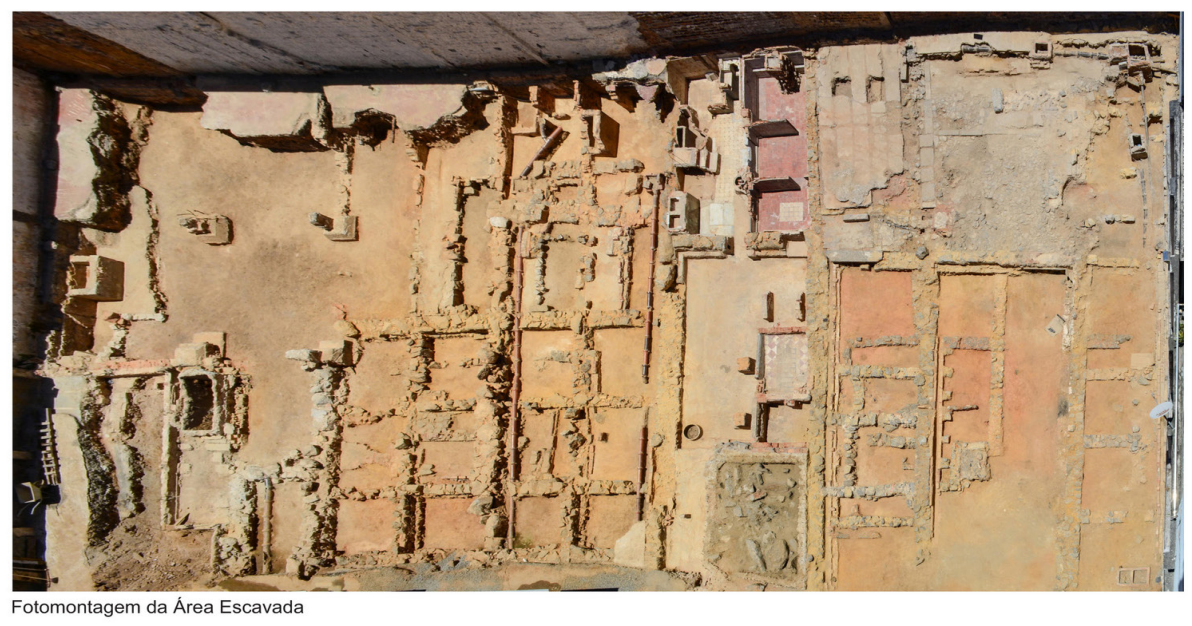

Figura 2: A área do terreno pesquisado totalmente escavada, expondo os alicerces de seis unidades habitacionais do século XIX

Foto: Margareth Dias

\section{OS RESTOS FAUNísticos}

A análise dos componentes do sistema alimentar dessas habitações revelou o seguinte: no que diz respeito aos restos faunísticos, foram encontradas cerca de 300 peças ósseas, sendo quatro inteiras, 294 fragmentos, um osso de peixe e uma valva de Ostrea sp., pertencentes às classes Mammalia, Aves, Pisces e ao Filo Mollusca. Os dois últimos exemplares não foram inseridos nos cálculos percentuais em razão de sua baixíssima representatividade no registro arqueológico estudado. Os mamíferos foram analisados e identificados como bovinos (234 fragmentos, $79 \%$ ), seguidos de caprinos (cinco fragmentos, $2 \%$ ), suínos (seis fragmentos, 2\%) e 10 fragmentos não identificados (3\%). Foram encontrados ainda 43 fragmentos de ossos de aves, sendo 40 de galinha e três indeterminados (13\% da amostra) (Gráfico 1). 
O sistema alimentar da cidade do Rio de Janeiro na primeira metade do século XIX Entre a conservação e a transformação

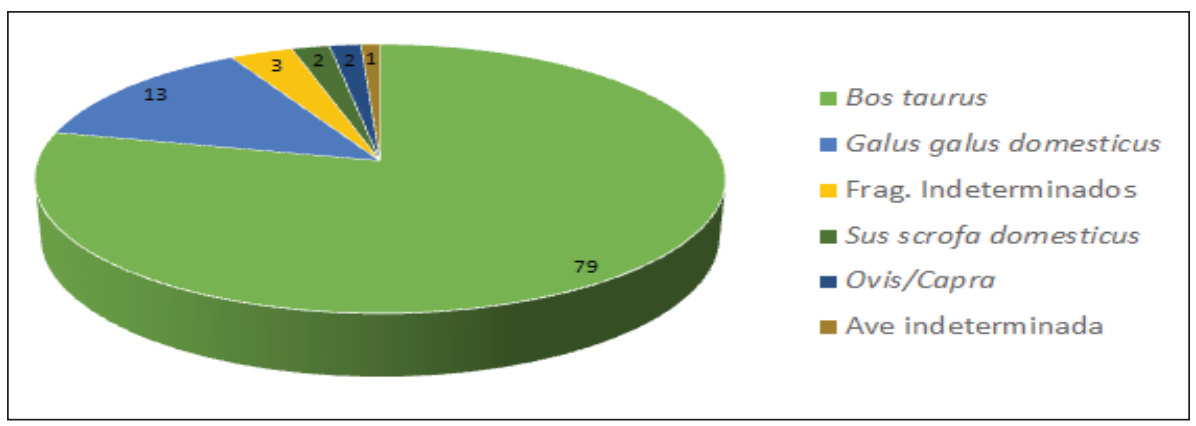

Gráfico 1: Percentuais dos restos faunísticos recuperados

As porções de carne de boi consumidas foram aquelas relacionadas aos ossos dos membros posteriores, às costelas, aos membros anteriores e às vértebras (Figura 3), relacionados inequivocamente aos cortes dos músculos traseiros e dianteiros (Gráfico 2), que correspondem a porções de carnes duras, menos valorizadas e de custo mais baixo ${ }^{1}$, adequadas para o preparo em meio líquido, na forma de cozidos e ensopados.

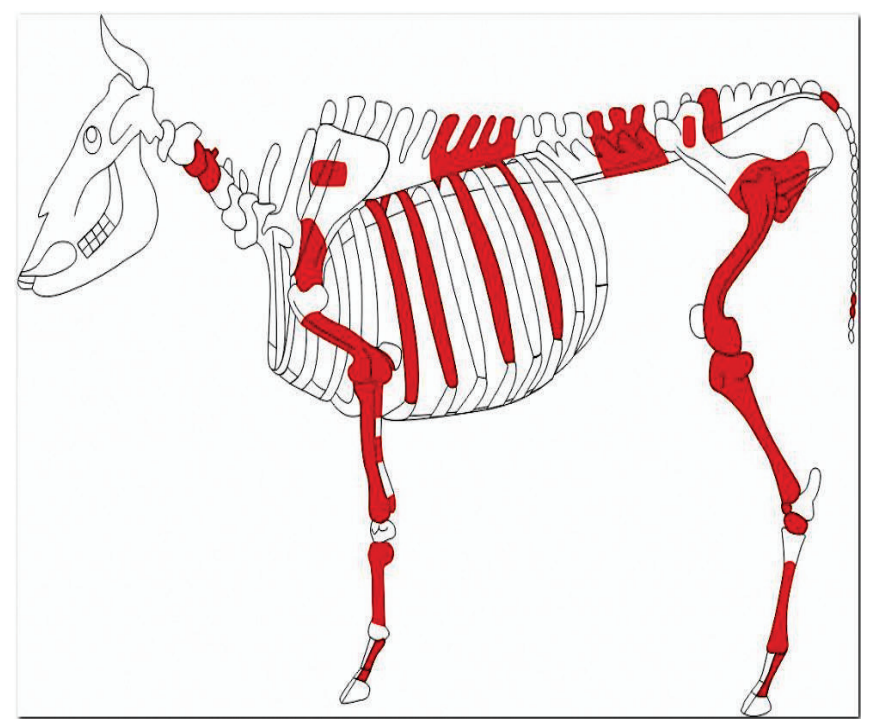

Figura 3: Em vermelho, os ossos de bovídeos encontrados, que correspondem aos cortes de carne consumidos

Fonte: <https://ru.depositphotos.com/6194483/stock-illustration-skeleton-of-cow.html>. Desenho: Martha Locks. 


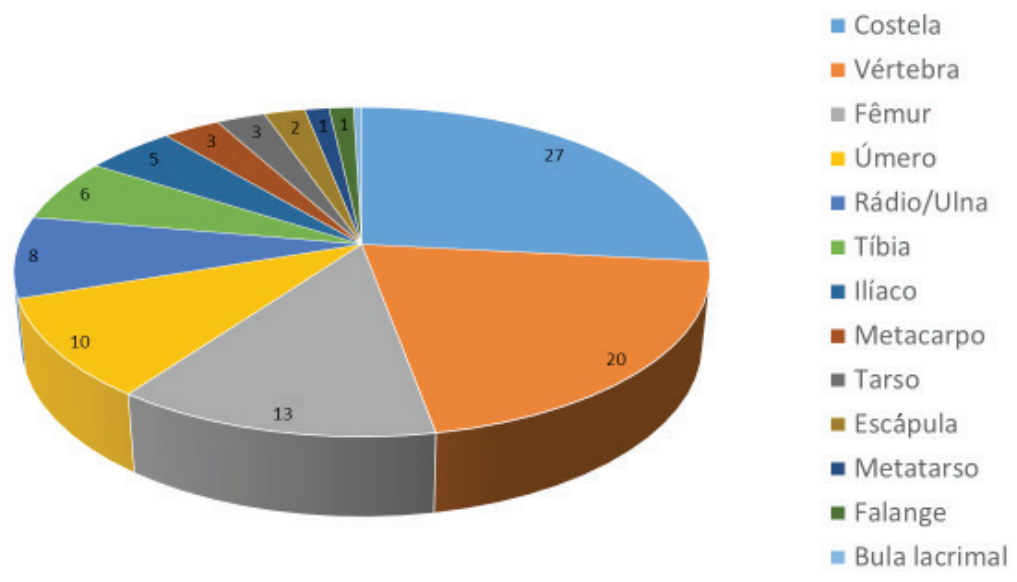

Gráfico 2: Percentuais dos ossos de bovídeos por região anatômica

Apesar de muito fragmentados, é possível afirmar que os ossos recuperados são subprodutos alimentares, em decorrência da presença de três tipos de cortes ósseos: a) por impactos sucessivos, através de instrumento cortante como cutelo ou facão, resultando em fraturas irregulares; b) por serra, produzindo estrias regulares e unidirecionais; e, por fim, por incisões bem definidas para fins de descarnamento. Além do consumo da carne propriamente dita, há outros padrões de fracionamento dos ossos, como corte transversal e, por vezes, longitudinal cuja recorrência parece indicar a retirada do tutano para consumo (Figura 4) ${ }^{2}$.

2 Fisher 1995, O’Connor 2013. 


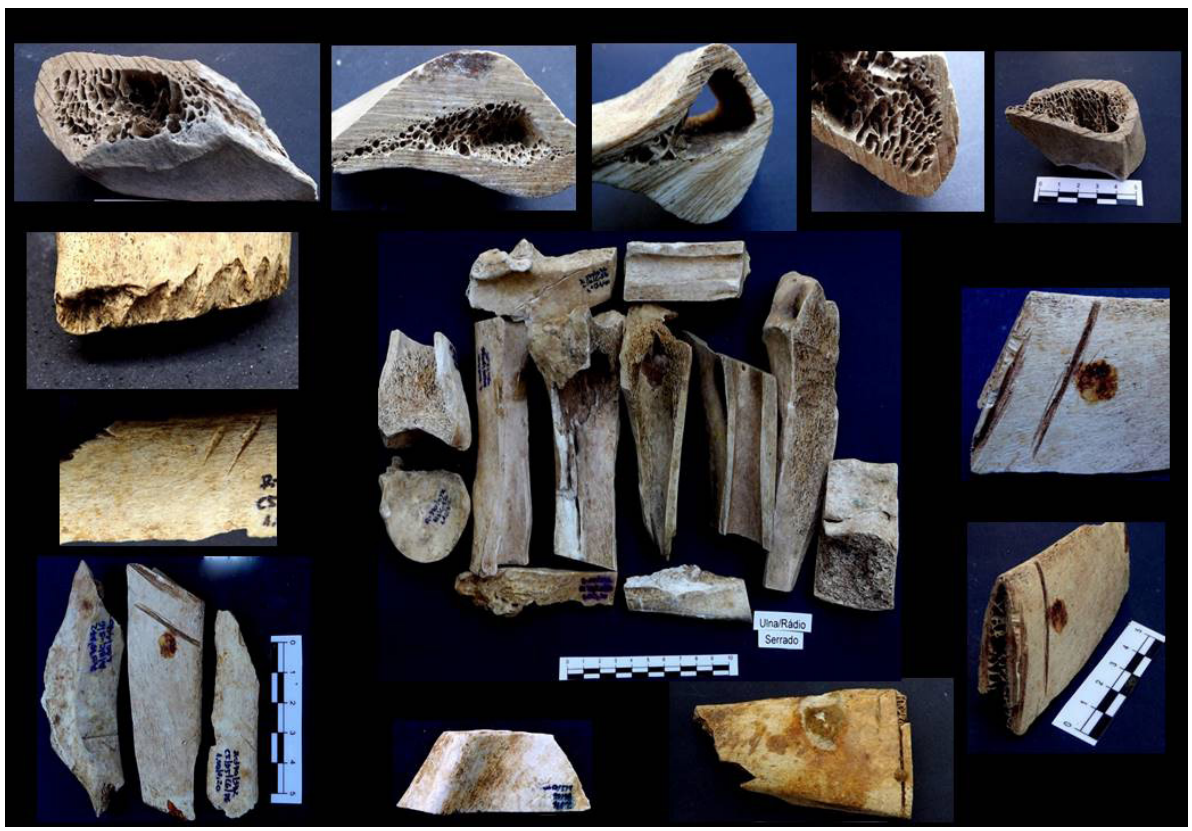

Figura 4: Evidências de corte por serra, por instrumento cortante, marcas de descarnamento e ao centro, fraturas longitudinais para retirada de tutano

Fotos: Andrea Jundi, 2015

\section{As PANElas de bARro PARA O PROCESSAMENTO DA COMIDA}

Com relação ao processamento dos alimentos, amostra dos recipientes de barro encontrados e analisados é composta por 189 fragmentos, dentre os quais foram identificados 32 recipientes, sendo 20 panelas, quatro para estocagem de alimentos sólidos e seis para líquidos, além de dois fogareiros. Trata-se de poucos recipientes, relacionados possivelmente a grupos domésticos pequenos, com um número reduzido de indivíduos. Os vasilhames usados no preparo de alimentos constituem a maioria da amostra $(62,4 \%)$, incluindo as panelas globulares e outras de formas diversas, cuja função culinária pode ser inferida pela presença de fuligem nas suas superfícies externas (Gráfico 3).

Nesse conjunto, destacam-se as formas globulares, dentre as quais uma panela apresenta-se quase completa. Trata-se de uma forma com grande persistência temporal na cidade, aparecendo em contextos datados desde o século XVII, estendendo-se até, pelo menos, meados do XIX. Em Portugal, ela aparece na região de Almada, associada a um contexto do final do século XVII e começo do XVIII. Ao estudarem essa cerâmica, os pesquisadores definiram-na como não compatível com o período em questão, relacionando-a 
aos escravos que lá chegaram ${ }^{3}$. Acrescente-se ainda a pesquisa desenvolvida por Deagan ${ }^{4}$ na colônia de Puerto Real, no Haiti, durante a qual escavações arqueológicas encontraram vasilhames cerâmicos com a mesma morfologia, também interpretados como de influência tipicamente africana.

A presença desse tipo de forma no sítio sugere, então, sua inserção em uma prática ligada ao uso de um tipo específico de panela que é multigeracional e que se associa, como sugerem diferentes linhas de evidências, às mulheres cativas provenientes da Africa Central, onde essa forma era frequente ${ }^{5}$, tal como foi mostrado no caso do século XVIII (Figura 5).

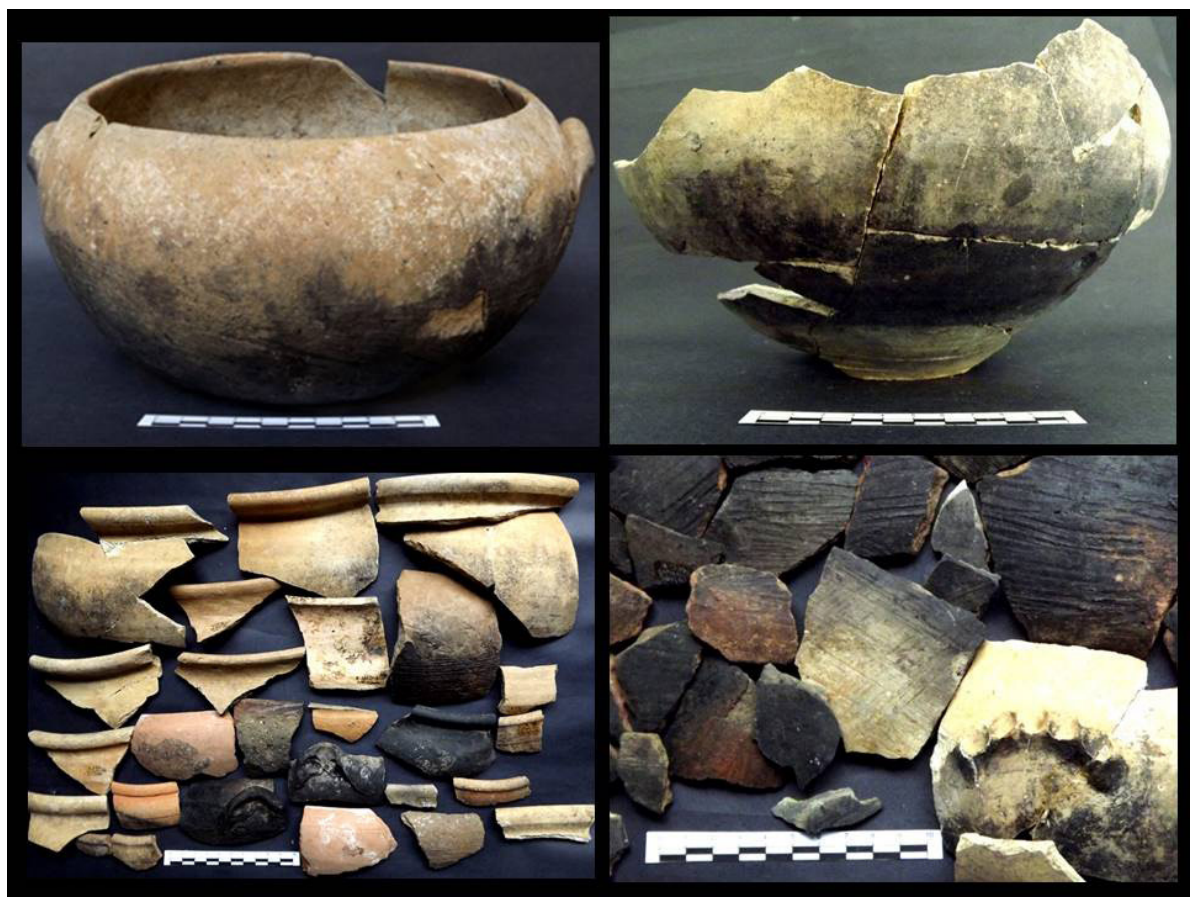

Figura 5: Panelas de barro globulares

Nota: Embaixo, à direita, panelas com decoração escovada e asa digitungulada. Fotos: Andrea Jundi, 2015

É sabido que na primeira metade do século XIX as cozinhas urbanas do Brasil eram ocupadas pelas mulheres escravizadas, responsáveis por grande parte do trabalho doméstico, incluindo o preparo de alimentos. Nesse sentido, a presença desse tipo de forma parece um indicativo, ainda que discreto, da

\footnotetext{
3 Barros, Cardoso 2008.

4 Deagan 1996.

5 Souza 2015.
} 
presença de cativas oriundas da África Central nessas unidades domésticas e, mais especificamente, na formulação cotidiana de práticas alimentares com uma base cultural proveniente do continente africano ${ }^{6}$.

Entre as panelas, foram identificados fragmentos de pequenas bases planas, recorrentes em diferentes contextos brasileiros, tanto urbanos quanto rurais (Souza 2015). Ainda que algumas variáveis sugiram uma influência cultural africana nas atividades ligadas ao preparo de alimentos, como consta acima, a presença desse tipo de base faz lembrar que o aparato material ligado a sistema de alimentos nesse e em outros sítios do Rio de Janeiro esteve sujeito a diferentes influências culturais. Essa ponderação é possível de ser feita na medida em que o uso de bases planas não é comum nas diferentes tradições cerâmicas ligadas ao contexto do tráfico atlântico de escravos, tendo resultado, portanto, de uma demanda dos segmentos livres eurodescendentes, tal como também foi observado para o século XVIII.

A análise da amostra sugere também que os recipientes empregados no preparo de alimentos tinham capacidade baixa, com diâmetro variando entre 10 e $28 \mathrm{~cm}$. Esse perfil é concordante com o que tem sido recuperado, de modo mais geral, em sítios em contextos urbanos, geralmente associados a grupos domésticos pequenos, com poucos indivíduos escravizados.

Foram identificados quatro vasilhames de borda larga, possivelmente para estocagem de sólidos, especialmente cereais, correspondendo a 12,6\% das peças, além de fragmentos de recipientes de borda direta, outros de borda constrita, de moringas fragmentadas e um de outra peça com gargalo largo, relacionados ao armazenamento e transporte de líquidos, totalizando $18,8 \%$ da amostra (Gráfico 3).

6 Deagan 1996; Barros, Cardoso 2008. 


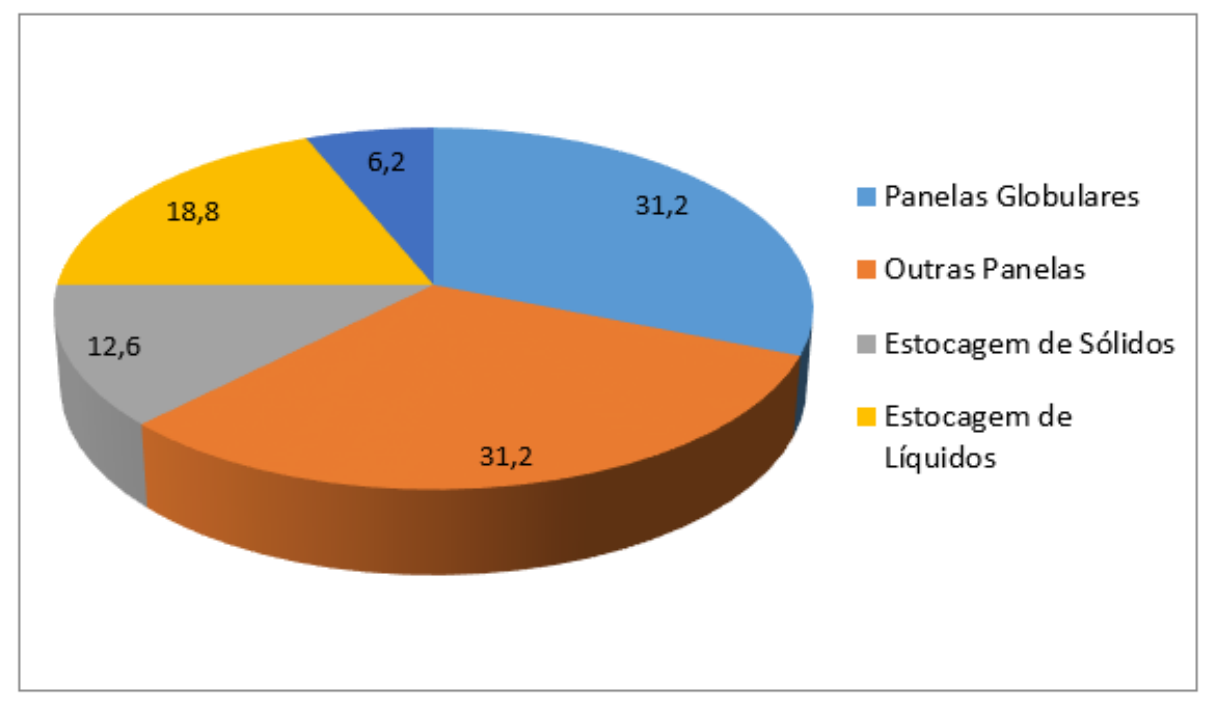

Gráfico 3: Percentuais dos recipientes destinados ao processamento e estocagem de alimentos

No que diz respeito à decoração, os recipientes usados no preparo de alimentos apresentam evidências de decoração plástica, especialmente nas panelas, destacando-se o escovado e incisões no corpo das peças, além do digitungulado em algumas asas, técnicas também muito frequentes no período.

\section{As louças para Serviço e consumo dos alimentos}

Quanto às louças destinadas ao serviço e consumo de alimentos ${ }^{7}$, foram analisados 347 fragmentos de faiança fina inglesa branca, sem decoração, dentre os quais foi identificado um número mínimo de 260 peças. As formas preferencialmente escolhidas para o serviço e consumo dos alimentos durante as refeições foram as fundas, representadas por malgas $(49 ; 18,5 \%)$, pratos fundos $(23 ; 8,9 \%)$ e sopeiras e tigelas $(43 ; 16,5 \%)$. Em menor quantidade estão as formas rasas, totalizando $13,5 \%$ da amostra, além de duas travessas (Gráfico 4). 
Abstract: This article presents a synthesis of the material culture related to food system of some nineteenth century households at Riachuelo street, Rio de Janeiro downtown, such as faunal remains, earthenwares, and pottery used to serve and consume food. The analysis of these components revealed some contradictions of the socio cultural system in the first half of the nineteenth century in Rio de Janeiro. Although major changes at different levels and the rise of french-english values related to daily dietary patterns could be identified, that ambivalent society in change seems to have maintained her colonial food traditions from what it would just be free at the beginning of the next century.

KEYWORDS: urban archaeology, nineteenth-century Rio de Janeiro, english tablewares, animal bones, multiculturalism.

A partir dos resultados obtidos para o século XVIII, apresentados nos artigos precedentes, foi nosso objetivo investigar a seguinte questão: a súbita transferência da capital do Império Português para o Rio de Janeiro, em 1808, provocou uma transformação radical na cidade pequena e acanhada, totalmente despreparada para receber a Família Real e sua numerosa comitiva. A vida cotidiana, no que diz respeito às rotinas diárias e formas de comportamento, sofreu um forte abalo, tornando imperiosa a necessidade da sua reordenação, de modo a suprir as novas necessidades que se impunham. Somada ao rompimento do pacto colonial, ela determinou profundas mudanças em diferentes níveis, que se estenderam ao longo da primeira metade do século XIX. Indagamos, no caso, se o domínio das práticas alimentares - um dos mais conservadores da cultura e um dos que mais resiste a transformações - se deixou permear por essas mudanças, ou se manteve seu apego à tradição setecentista.

Com esse objetivo, selecionamos uma amostra bem contextualizada da primeira metade do século XIX, para fins comparativos com o século XVIII. Trata-se, no caso, de uma pesquisa arqueológica que foi realizada preventivamente, em decorrência da construção de uma edificação comercial em um terreno composto por cinco lotes, à rua Riachuelo, na Lapa, centro do Rio de Janeiro.

A ocupação dessa área remonta aos primórdios da colonização da cidade, quando foi aberto, em 1567, um caminho que ligava seu núcleo original às terras dos jesuítas, no interior. No século XVIII, aí se estabeleceram algumas das famílias mais abastadas da sociedade, que povoaram com chácaras e casas ajardinadas as duas margens da estrada, que passou a ser designada como Caminho de Mata Cavalos (Figura 1). Ao longo da primeira metade do século XIX, essa ocupação foi ainda mais adensada. O velho Caminho de Mata Cavalos foi arruado, mantendo seu perfil de área nobre da cidade, com belos solares e imponentes casarões. 


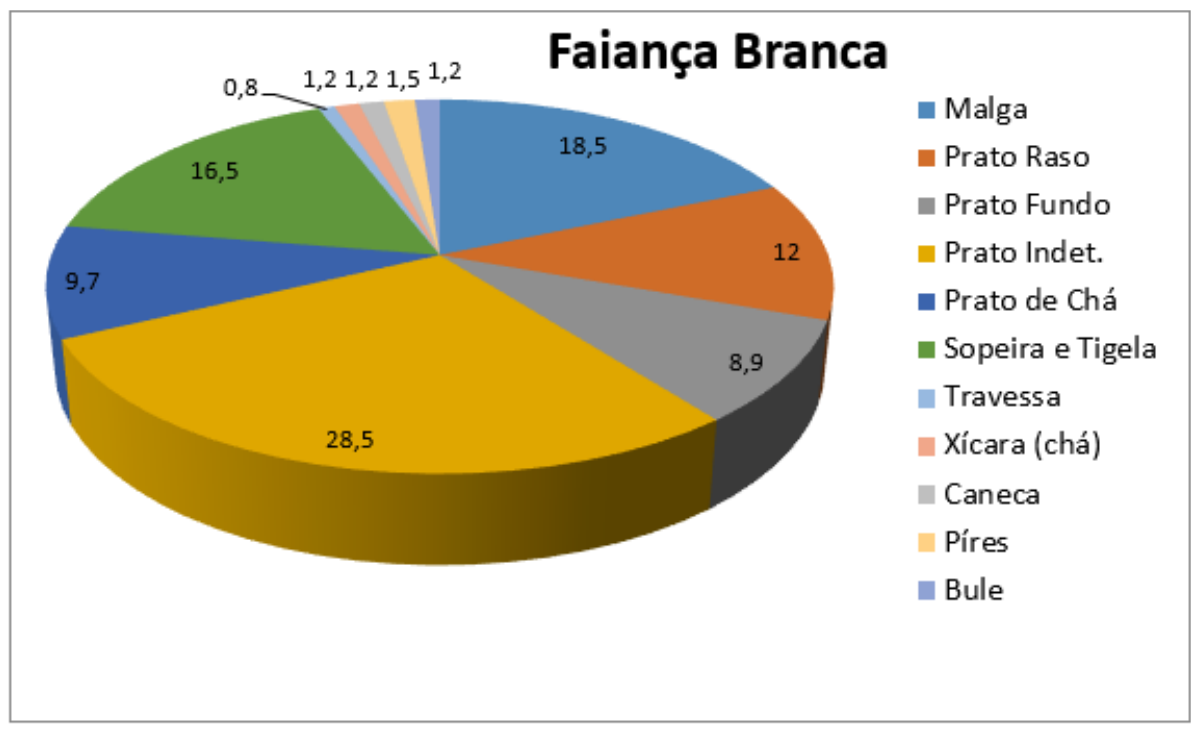

Gráfico 4: Percentuais das formas em faiança branca destinadas ao serviço e consumo de alimentos

Quanto aos itens relacionados ao armazenamento, consumo e serviço de bebidas quentes, destacamos três bules, três xícaras de chá, três canecas, representando cada um $1,2 \%$ das peças identificadas, além de quatro fragmentos de píres e 25 de pratos de chá $(9,7 \%)$.

No que diz respeito aos pratos para as refeições diárias, foi observada uma quantidade ligeiramente maior de peças rasas (12\%) que fundas $(8,9 \%)$. No entanto, um número expressivo de pequenos fragmentos de bordas de pratos não foi identificado, não sendo possível saber se são fundos ou rasos $(28,5 \%$ da amostra). Caso fosse viável fazer essa distinção, esses percentuais poderiam ser alterados. Trata-se de pequenos fragmentos de bordas que não permitem uma identificação mais precisa.

A faiança fina inglesa decorada caracterizou-se por um grupo de louças com superfície modificada por diferentes técnicas decorativas: a) pintada à mão com motivos florais policrômicos e em flow blue, e incisões com pintura azul ou verde compondo os padrões blue ou green edge; b) transfer printing com motivos chinoiserie, paisagens e florais, predominantemente na cor azul, além de cinza escuro, verde e vinhoso; c) relevos em engine turned. Integram ainda a amostra os padrões dipped, banded e spongeware (Figura 6). 


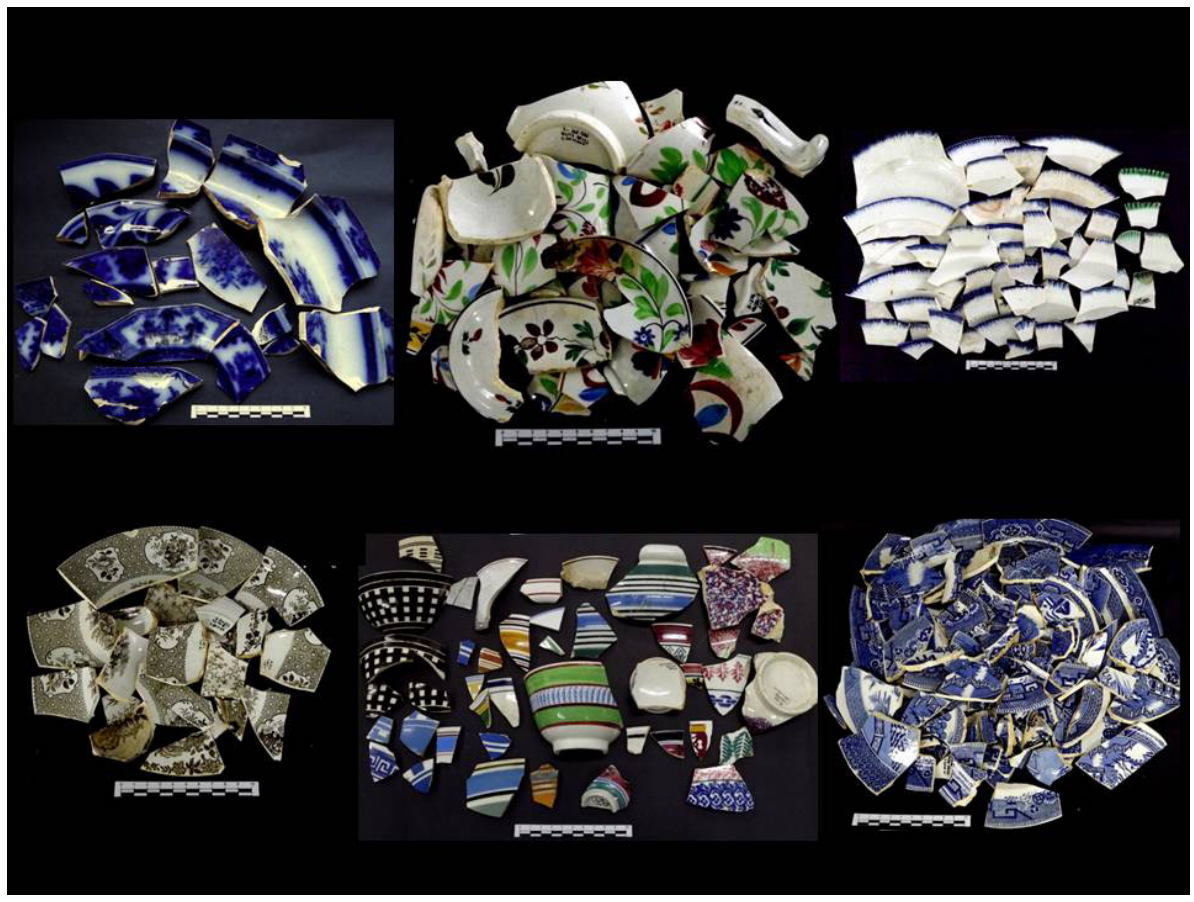

Figura 6: Diferentes técnicas decorativas da faiança fina inglesa

Nota: Acima, decoração pintada; abaixo, nos extremos, transfer printing; e no centro, padrões engine turned, dipped, banded e spongeware.

Fotos: Andrea Jundi, 2015

Foram analisadas 526 peças de faiança decorada e identificado um número mínimo de 304 peças, com predomínio da decoração em transfer printing, correspondendo a 213 peças (70\%), seguido do padrão blue e green edge com 36 peças $(11,8 \%)$ e outros (Pintado à mão, engine turned, banded e spongerware).

Quanto às formas, que remetem diretamente aos hábitos alimentares dessas unidades domésticas do século XIX, observamos que foi mantida a preferência pelas formas fundas, como ocorreu na amostra de louças brancas não decoradas, anteriormente descrita. Entre elas, malgas (82; 27\%), pratos fundos $(28 ; 9,2 \%)$, sopeiras e tigelas $(16 ; 5,4 \%)$. As formas rasas ocorreram em menor quantidade: pratos rasos $(20 ; 6,5 \%)$ e travessas $(13 ; 3,2 \%)$. As malgas foram as mais recorrentes, especialmente as com decoração em transfer printing (40 peças) (Gráfico 5). 


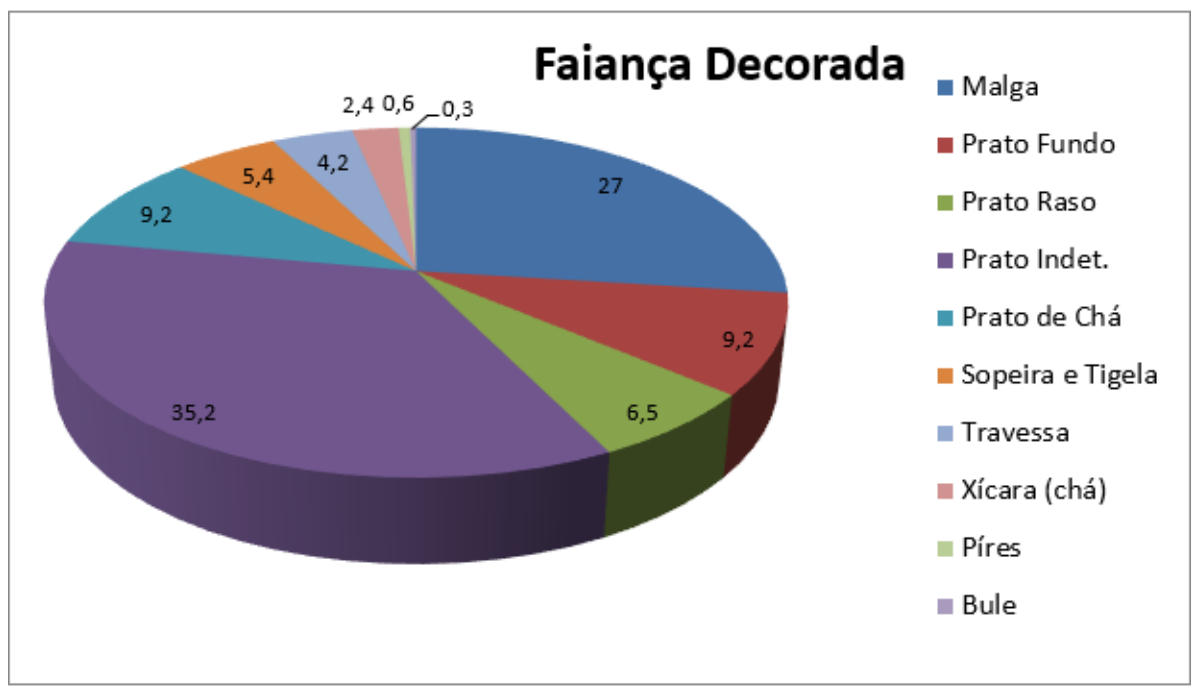

Gráfico 5: Percentuais das formas em faiança decorada destinadas ao serviço e consumo de alimentos

Novamente a amostra de pratos em faiança decorada apresentou um grande número de peças indeterminadas, fundas ou rasas, correspondendo a 107 peças, 35,2\%. Neste sentido, se possível fosse identificá-las, talvez a discreta preferência pelos pratos fundos $(28 ; 9,2 \%)$ poderia ser ampliada em relação aos rasos $(20 ; 6,5 \%)$, coadunando-se com o perfil geral da amostra cuja maior recorrência é de peças fundas.

Destacamos ainda a ocorrência de exemplares em faiança decorada relacionados ao consumo de bebidas quentes, tais como fragmentos de bule $(1 ; 0,3 \%)$ e de xícaras de chá $(7 ; 2,4 \%)$ em transfer printing, na cor azul, bem como de pratos de chá $(28 ; 9,2 \%)$.

\section{Considerações finais}

A análise dos diversos componentes do sistema alimentar desse conjunto de casas da primeira metade do século XIX, representativo da vida cotidiana de pessoas comuns, deixa à mostra algumas contradições. Em razão da abertura dos portos, em 1808, e o rompimento do pacto colonial, constata-se, por um lado, uma transformação radical no aparato de serviço de mesa. As faianças portuguesas dos séculos anteriores, que reinavam soberanas nas refeições, foram destronadas pelas faianças finas inglesas, agora onipresentes. A tal ponto que as faianças de Portugal simplesmente desaparecem dos registros arqueológicos oitocentistas. 
Isto implicou considerável alteração nas formas utilizadas pela população, com uma penetração maciça de pratos rasos ingleses, em contraste com os antigos pratos fundos portugueses. Tendo em vista que as formas guardam forte relação com sua função - no caso, o prato e o que ele está destinado a conter - seria de se esperar da mesma forma uma transformação nos padrões culinários, tendo em vista o caráter sistêmico do processo alimentar. Surpreendentemente, no entanto, foi mantido na amostra do século XIX um predomínio de formas fundas, sinalizando a manutenção, nas refeições, de sopas, caldos, cozidos, ensopados e guisados, tal como no século anterior, o que atesta o conservadorismo desse domínio. A mudança de dentro para fora se processa mais lentamente do que aquilo que é imposto de fora para dentro, de tal forma que no segmento das louças de mesa conviveram por algum tempo, lado a lado, a transformação e a conservação.

Quanto aos recipientes de processamento dos alimentos - as panelas - o conservadorismo também se fez sentir pesadamente. Foram mantidas as formas globulares atribuídas às mulheres cativas provenientes do centro-oeste africano, presentes na amostra do século anterior. Comandando as cozinhas, elas selecionavam seu equipamento de trabalho, sobretudo porque desapareceram, da mesma forma que a faiança, as louças de barro com forte influência portuguesa ou mesmo importadas de Portugal.

O consumo de carne manteve o mesmo perfil, com forte predomínio de bovinos, e, em menor escala, suínos, caprinos, e aves domésticas, tendo peixes e moluscos desempenhado um papel insignificante na dieta. A prevalência de cortes de carne dura e/ou nervuda, de custo mais baixo, se somada à grande quantidade de faianças sem decoração e com padrões decorativos também de baixo custo, permite supor que os grupos domésticos analisados tinham um poder aquisitivo relativamente limitado.

Embora passando por grandes transformações em vários níveis e já se deixando permear pelos valores franco-ingleses em ascensão, no nível das práticas alimentares cotidianas essa ambivalente sociedade em transição parece ter conservado predominantemente, na primeira metade dos oitocentos, as tradições culinárias dos colonizadores, das quais só viria a se libertar de meados do século em diante.

\section{REFERÊNCIAS}

Barros, L., Cardoso, G. (2008), "Cerâmicas manuais dos séculos XVI a XVIII de Almada, Cadaval e Cascais”, Revista Portuguesa de Arqueologia 11.2: 347-360.

Coysh, A. W., Henrywood, R. K. (1995), The Dictionary of Blue \& White Printed Pottery 1780-1880, Antique Collector's Club, Suffolk. 
O sistema alimentar da cidade do Rio de Janeiro na primeira metade do século XIX Entre a conservação e a transformação

Deagan, K. (1996), "Colonial transformation: Euro-American cultural genesis in the early Spanish-American colonies”, Journal of Anthropological Research 52.2: 135-160.

Fisher Jr., J. W. (1995), "Bone surface modifications in zooarchaeology", Journal of Archaeological Method and Theory 2.1: 7-68.

Landon, D. B. (2005), "Zooarchaeology and Historical Archaeology: progress and prospects", Journal of Archaeological Method and Theory 12.1: 1-36.

Miller, G. L. (1980), “Classification and Economic Scaling of 19th Century Ceramics”, Historical Archaeology 14:1-40.

Miller, G. L. (1991), "A revised set of CC index values for Classification and Economic Scaling of English ceramics from 1787 to 1880", Historical Archaeology 25.1: 1-25.

O'Connor, T. (2013), The Archaeology of Animal Bones, The History Press, Gloucestershire.

Souza, M.A.T. (2015), "When all bases are flat: Central Africans and situated practices in the eighteenth-century Brazil”, in P. P. A. Funari, C. E. Orser Jr. (eds.), Current Perspectives on the Archaeology of African Slavery in Latin America, Springer, New York, 77-97.

Wetherbee, J. (1985), A Second Look at White Ironstone, Wallace Homestead, Lombard.

Williams, P. (1981), Flow Blue China, Fountain House East, Jefferson Town. 